\title{
3D VIRTUAL MODELS FOR AN EARLY EDUCATION SERIOUS GAMING APPLICATION
}

\author{
D. Anastasiou ${ }^{1}$, T. Avgeri ${ }^{2}$, A. Iliodromitis ${ }^{1}$, V. Pagounis ${ }^{1}$, M.Tsakiri $^{3 *}$ \\ 1. Department of Surveying and Geoinformatics Engineering, University of West Attica, danastasiou@ uniwa.gr, \\ ailiodro@gmail.com, pagounis@uniwa.gr \\ 2.Pre-school teacher, Athens, theoavgeri@yahoo.gr \\ 3. School of Rural and Surveying Engineering, National Technical University of Athens, mtsakiri@central.ntua.gr
}

\section{Commission WG VI/1}

KEY WORDS: 3D modelling, visualisation, virtual environment, web learning, education, spatial thinking

\begin{abstract}
:
Visualization and conceptualisation of 3D objects are complex cognitive processes which are regarded essential from pre-school education to develop abilities linked to spatial and 3D thinking. The focus of this paper is to discuss the use of a virtual 3D environment as a pedagogical serious gaming platform that may help intensify learning processes. Recently, serious games are gaining popularity not only as games, but as promising educational tools too. This paper presents the creation of a simple 'serious game' where several tasks can be constructed that promote the 3D spatial thinking in pre-school education. Specifically, the creation of the virtual environment from a pre-school's indoor and outdoor environment was performed using geodetic and terrestrial laser scanning techniques. To increase the geospatial sense of pre-school children within the virtual environment, an application was developed with simple educational tasks within the 3D environment. The templates, for each section of the gaming application, have been developed using HTML5 and CSS3, in order that they are interactive and accessible to all smart devices. The paper concludes with a discussion on the experience gained towards supporting spatial thinking for pre-school children.
\end{abstract}

\section{INTRODUCTION}

Contemporary education in pre-school and primary education is focused on the development of horizontal competences often called key-skills. These cognitive abilities are regarded as crucial transversal skills that are needed to live and be active actors in the knowledge society. According to Gardiner (1983), one of the nine types in the theory of multiple intelligences, is the Spatial Intelligence (SI) and the spatial abilities which are considered essential transversal skills since humans use this form of reasoning in numerous daily activities (Sarno, 2012).

Spatial thinking refers to the ability to perform judgments in space and correctly define the reciprocal position of different objects in the surrounding environment. In other words, it is essential to solve spatial problems of navigation, visualise objects from different orientations and notice fine details about the shape, size, movement, as well as being able to envision and manipulate 3D models. With spatial intelligence, humans can interpret and make judgements about their whereabouts in the environment. Clearly, the capacity to picture spatial problems from different perspectives is the key to this type of intelligence. Humans with strong spatial perception are likely to "see the big picture" when solving problems. These are often referred to as visual learners and often possess photographic memory retaining images more vividly (Surtees et al., 2013).

With regards to education, research has shown that children who have been exposed to spatial skills are more likely to perform well in the STEM disciplines and follow a relevant career (e.g. Newcomb and Frick, 2010). In addition, it is believed that humans can improve their spatial abilities with training. Specifically, pre-schoolers who are better at visualizing spatial relationships develop stronger arithmetic abilities in primary school (e.g. Gilligan et al., 2017; Verdine et al., 2017; Zhang et al 2014). Also, in children, it is possible to promote numerical cognition, which is the base of mathematical cognition and academic achievement in later years, by strengthening their natural aptitude to deal both with numerical stimuli and spatial stimuli (Ponticorvo, 2019).

This spatial stimulus is offered to children mainly through their school and family activities through physical play and computer-based gaming. Pedagogical games can encourage children's motor and cognitive development, their ICT skills, and their higher-order thinking skills (such as logical thinking, planning, and strategizing). This aspect of game-based learning is seen as a key priority to enhance young people's 'constructionist' learning and ' 21 st century skills' (e.g. De Gloria et al., 2014).

In view of the above, this paper presents the development of a simple serious game for pre-school education purposes using a 3D model environment. The remainder of the paper comprises 4 sections. Section 2 provides a brief review of the literature on the applicability of serious games in pre-school education. Section 3 describes the methodology for developing the simple educational serious game discussed in this work and in section 4 preliminary assessment results from its use are provided and discussed. Finally, section 5 provides the conclusions and remarks for future directions of this work.

\section{SERIOUS GAMES FOR SPATIAL THINKING}

It is accepted nowadays that use of the virtual environment may promote, assist, and support the learning process in the preschool education activities. Papert (2003) supports that the use 
of ICT in classroom, not only encourage learning but extends it by providing new possibilities for learning, thinking and growing emotionally as well as in a cognition sense. ICT when effectively used, can help children learn and achieve to the best of their abilities (Gillespi, 2006). The use of technology can expand children's cognitive and social skills and help them develop good relationships amongst them. Developmentally appropriate software and digital tools engage children in dialogue and creative play while creating opportunities for problem-solving (EAICT, 2011). The use of ICT in classroom as an integral and complementary part of the curriculum is supported by both research and practice. However it is also clear that ICT cannot replace other educational activities and processes which are significant to this age, such as real world games, experiencing materials and exploration (Clements and Sarama, 2002; Haugland, 2000; Mohammed and Mohammed, 2012)

In the context of the integration of ICT in the classroom, digital games can be a new learning tool in educational practice, if used properly. Papert (1993) argues that digital games can give a fast and therefore more interesting rhythm to teaching, in contrast to conventional means, which make the teaching process slow and boring. Moreover, since most students are already familiar with digital games and their technology, it is more likely to enjoy a learning experience integrated in digital games (Prensky, 2002). Several studies that have explored the use of 3D virtual environments in education and their capability to support learning, suggest that activities within the virtual environment enhance collaborative learning and the interaction of the members involved, creating new opportunities for teaching and learning (Duncan et al., 2012; Dalgarno and Lee, 2010). Fokides (2020) in his critical examination of many projects involving the use of 3D digital games, argued that the use of digital educational games results in better learning gains and conceptual understanding. However, the challenges in embedding serious games into formal education lie in their ability to demonstrate the complexity and interconnectedness of issues. These challenges can be approached using three frameworks, namely the identification of learning goals, identification of teaching enhancement and game assessment. In the area of pedagogy, the learner needs to be active while playing rather than being cognitively overloaded.

There is also evidence that digital games can be effectively incorporated into an early childhood school setting where the adult plays a significant role in providing developmentally appropriate and intentional opportunities for digital play to occur. (Wong-Powell, 2020). Another study illustrates how children make meaning, transform and play while engaging with various applications and how children's self-initiated play with application's design shifts the balance of authority that typically exists between adults and children (Kjällander and Moinian 2014).

Dalgarno and Lee (2010) in their review of applications of 3-D Virtual Learning Environments (VLEs) explored the potential learning benefits of VLEs and suggest that the affordances of such environments include the facilitation of tasks that lead to enhanced spatial knowledge, representation, greater opportunities for experiential learning, increased motivation/engagement, improved contextualisation of learning and richer/more effective collaborative learning as compared to tasks made possible by $2-\mathrm{D}$ alternatives. These benefits have been observed to preschool settings as well. Martinez et al. (2014) explored how guided interaction with 3D apps can fit into a preschool setting, how it can help children learn through playing and how it can improve their learning outcomes. Their findings indicate that the use of 3D interactive applications promote active behavior, communication skills and all kinds of interactions in the classroom and help students achieve their learning goals faster.

\section{DEVELOPING A SIMPLE SERIOUS GAME}

\subsection{Game Design}

One of the biggest problems of educational games to date is the inadequate integration of educational and game design principles (e.g. Kiili, 2007) and this is also due to the fact that digital game designers and educational experts do not usually share a common vocabulary. Most new generation serious games and virtual environments adopt a discovery and inquirybased learning strategy whereby students learn basically by exploring contents and solving problems. Whilst this can be appealing, for small children though, this approach is tricky. Studies have shown that minimally guided instruction is less effective and efficient as they have no sufficient knowledge to provide "internal" guidance (e.g. Kirschner et al., 2006).

Learning is a complex activity that needs several gradual steps, that have to be supported by various tools (e.g., paper and digital, reading and writing, etc.) and generally have to be guided usually by the teacher, in order to be useful for the learner and not cause acquisition of misconceptions or of incomplete/disorganized knowledge. The adult teacher/educator can help the child to get the meaning of what he/she is doing, in particular at the first steps.

Considering the above and bringing the design pattern concept into the educational games field, Kiili (2010) identified several patterns addressing crucial educational aspects that game designers should take into account when designing educational games. These patterns include integration of game elements and learning objectives, cognition that stimulates users, presentation to ensure that the player's processing of the content is effective, social interaction that facilitates teaching and learning and finally presentation patterns that enables wrapping the whole gaming experience into a meaningful and motivating package.

Based on the above, a simple multimedia learning user-interface virtual environment for a simple pre-school education game was developed and presented here. The pre-school user does not only learn the content, but also learns how to deal with the synthetic programmed environment. The ease of use, and the uniformity of the interface, has great implications, since they may make possible a higher level of concentration on the material being studied The design of the interface was made such to provide a representation of clear, consistent and attractive communication. The interface is the computer screenthe display landscape. The game can easily be transferred to PDA form.

In simple terms, the game environment consists of: (1) a spatial organization, which in this case is the school environment that induces spatial information processing and provides landmarks to support orientation. The children (users of the virtual environment) have already got good knowledge about the building and the outdoor areas, and (2) contextualized tasks, that are spread around the environment. The tasks embody units 
of knowledge that can be discovered by the user. This is based on the Task Based Learning (TBL) theory (Willis, 1996) that stresses the importance of concrete, focused activities to construct knowledge and develop skills.

In the developed game, the mode can often be in navigation (inside buildings or outdoors), and does not follow a detailed story specification. A high-level challenge (e.g., a treasure hunt) can be easily included that puts children into a cooperative cooperation through explorations of their environment. The preschool children can explore the environment accomplishing missions involving a sequence of small tasks, each of which has a specific, limited instructional target. The missions' complexity, given by the difficulty of the tasks and the environment to be explored, can grow up gradually towards ever more complex objectives. The tasks are templates with different contents, thus keeping the cognitive load low. Moreover, the development of tasks is supported by a toolkit which can allow teachers to develop/customize content (e.g. Bellotti et al., 2010). The tasks are of different type which support different learning activities depending on the teacher strategy. They also vary on the thematic topic the teacher must cover and some examples implemented in the developed game are given in section 4 .

\subsection{Data Collection}

The object of interest was a nursery school building which accommodates two different schools. It is a state school that belongs to the municipality of a suburb in Athens. This is a new and modern building with a built area of about $500 \mathrm{~m} 2$ and field area of 2 acres. It accommodates about 70-80 pre-school children.

Regarding the data collection, this was performed using the Leica BLK360 laser scanner (www.leica-_geosystems.com in two phases. In the first phase, the indoor and outdoor environment of the kindergarten were scanned. The scanner has the advantage that it is portable and light, while it is very easy to use and fast in data acquisition as it can capture 360,000 points per second. A full $360^{\circ}$ scan needs less than 3 minutes to be completed.

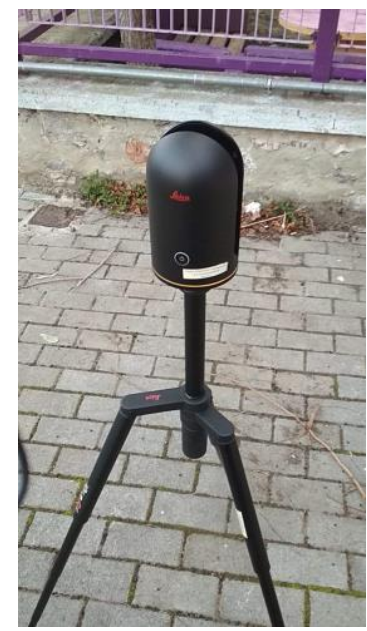

Fig. 1. The BLK360 laser scanner during data collection

A total of 28 setups were required to fully create the 3D virtual model. The setups were chosen in a way that each setup scans as much area as possible, while avoiding occluded areas during data capture. An overlap of at least $30 \%$ with the neighboring set-up was achieved. For the full coverage of the school, approximately 50 million points were obtained, with a scan resolution of $4.9 \mathrm{~mm}$ at $10 \mathrm{~m}$. The maximum distance between two neighboring stops was about 10m (Fig. 2).

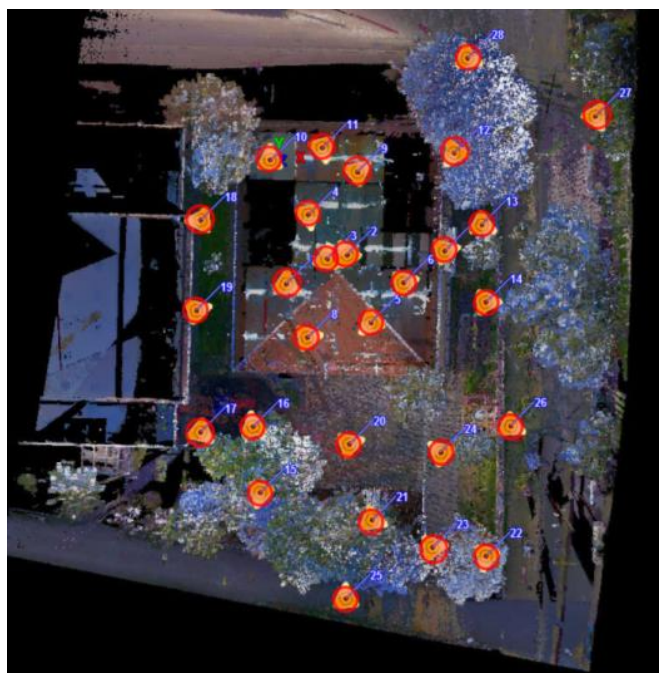

Fig. 2. Top view of area showing laser scanner set-ups

In the second phase, measurements were made using total station surveying. Reflective targets were positioned on different surfaces of the building. The targets were used as checkpoints during the model creation process (Fig. 3). A closed traverse was established around the school and the checkpoints were measured with total station in a local coordinate system. The measurement accuracy for each target was $5 \mathrm{~mm}$. In this way, the internal accuracy and the correct scale of the model are ensured.

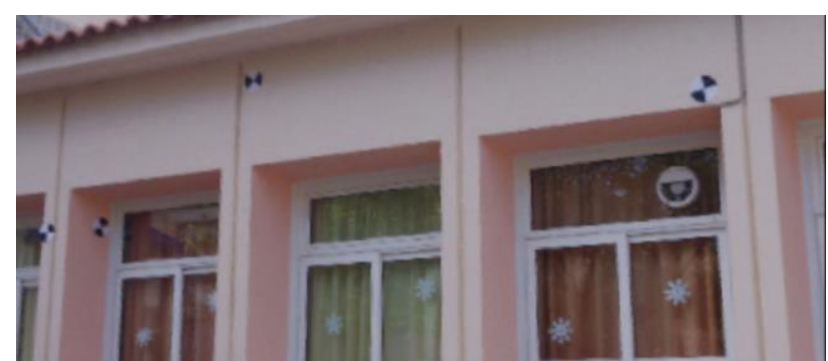

Fig. 3. View of targets

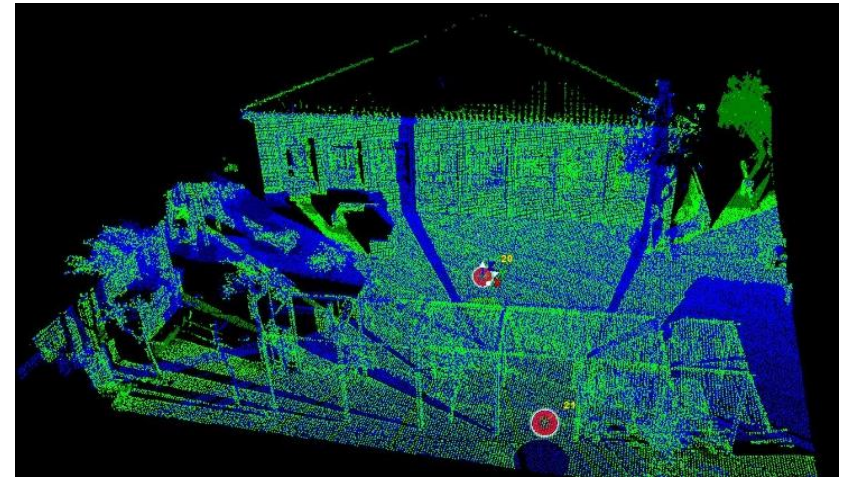

Fig. 4. View of aligned point cloud of school and outdoor area 
Additionally, a digital air flow tracker was used to measure the temperature to characteristic positions of the building. Finally, digital photos of the school were taken. Both temperature and photos were later incorporated into the final 3D model.

The acquired point clouds were processed using the proprietary software Cyclone (leica-geosystems.com). Although the point clouds could be registered without the use of control points, the measurements from the reflective targets were used so that to achieve higher accuracy of the registered model and ensure internal precision. The RMS of the point cloud registration was achieved to $0.016 \mathrm{~m}$, which is considered satisfactory for the needs of the specific application (Fig. 4). The georeferencing of the registered point cloud was achieved through the measured targets in the same local coordinate system that was established through the survey measurements of the traverse. From the process of the point cloud, the three-dimensional model of the school was produced. The final model is a textured colored mesh, using the photos taken during the scanning process.

\subsection{Geo-tagging}

From the merged point cloud, a number of products were created including the meshed model and the ortho-photo models with texture (e.g. RGB, gray scale etc) as seen in Fig. 5a, b and Fig. 6a, b. When all 3D models were created, they were imported in the platform with suitable software offering interactive measuring tools. In this work, the proprietary Leica Geosystems TruView Enterprise software was used where the online user can navigate inside and around the buildings.

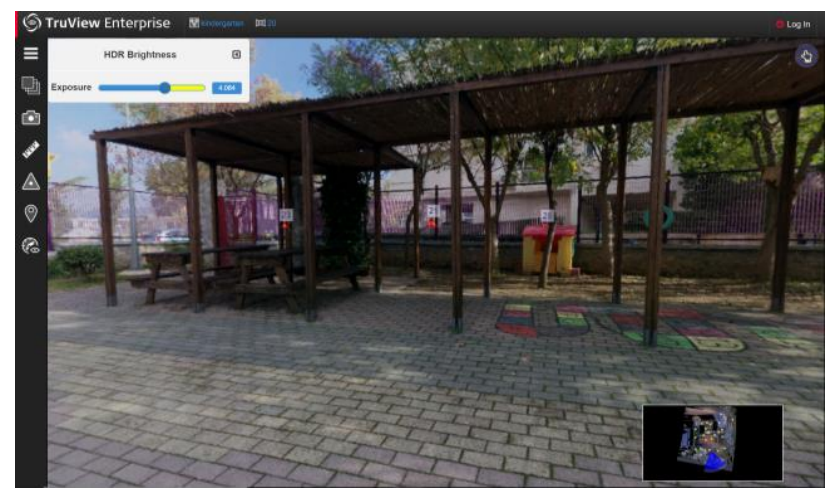

(a)

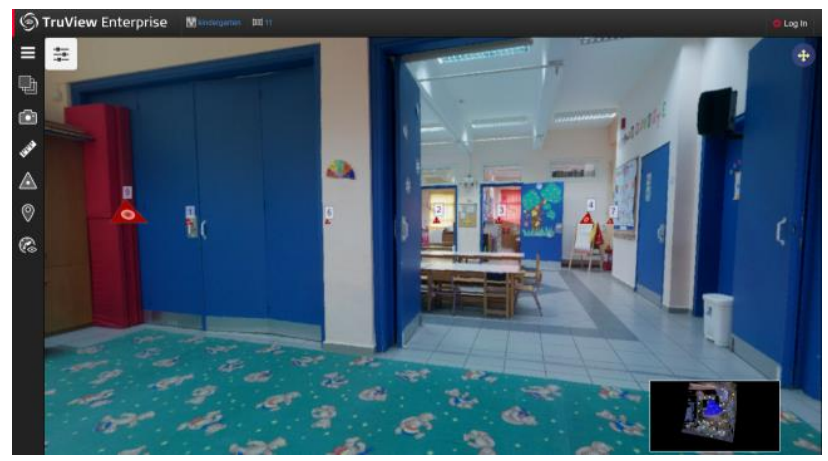

(b)

Fig. 5. Views of the model within TruView (a) outdoor area (HDR layer) (b) internal area of school (RGB layer)

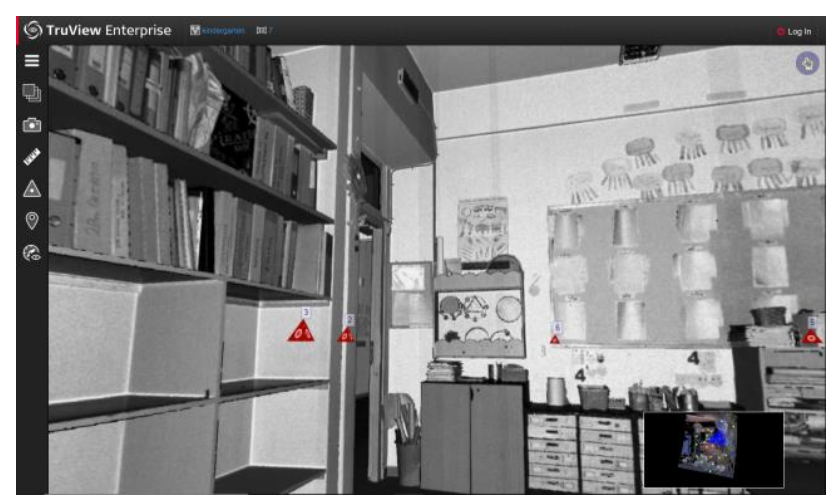

(a)

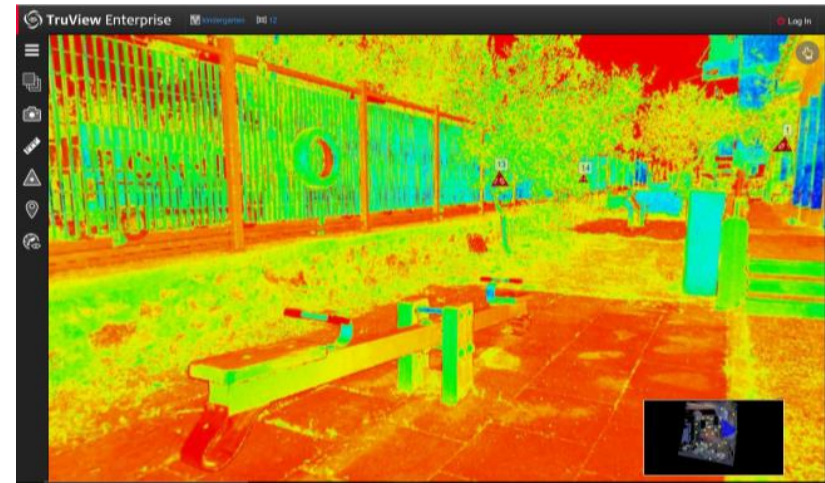

(b)

Fig. 6. Views of the model within TruView (a) indoor area (intensity grayscale) (b) outdoor area (???)

The final product is accessible via the Internet using the Leica Geosystems TruView Enterprise platform. The children, as users can navigate through the school space as if they were there. They can turn $360^{\circ}$, and zoom to specific positions which are numbered clearly. An additional feature is that they can measure dimensions and areas with an online ruler.

The final model is a textured coloured mesh. The children can view, pan, zoom and measure in the model environment. The use of geotags is another feature that was included in the model to help the children investigate and interact with the 3D model.

In the current application, geo-tagging was used as as a portal, so that the children can explore both qualitative and quantitative information as well as spatial correlations between objects. Tagging and hyperlinks are the simplest forms of digital augmentation to the content of a basic representation. Also, tags allow to add links in brief labels or texts (e.g., landmark name and description, embedded story, comments, question/answer, decision node, hints, clues), to reference them with markers on images or digital maps or using GNSS positions in order to remember where was found that particular information, reference data and clues, and to which location they refer. Geotagging is a fast-emerging trend in digital environments. The presence of geographically relevant metadata with images and videos has opened interesting research avenues within the multimedia and computer vision domains. The accessibility of geographically pertinent tags with pictures opens new data mining possibilities for spatial thinking activities.

For the specific 3D model, a POI (Point Of Interest) collection was established using GPS and loaded on the model. The POIs 
were selected both internally and at the outdoor area of the school representing features of interest for sharing multimedia artistic and educational content (photos and videos). For each geo-tagged POI, there is a metadata information stored in the TruView model. Besides the basic description about the set-up medata (e.g. scanner used, set-up date, identification number etc), there is information about the coordinate system, panorama metadata, view details, resolution and other (Fig. 7).

It is envisaged that the current game will be enriched by allowing the pre-school children to combine their knowledge and through their 3D tour of the school as a game, answering questions by combining images or videos. The templates, for each section of the gaming application will be developed using HTML5 and CSS3, in order that they are interactive and accessible to all smart devices. Access to each section of the application will be allowed through the geotag points, created in the 3D virtual model of the kindergarten. A geotag will lead the child to a short game through a link in the application. The child then may watch a relevant video, or complete a game with pictures etc. After completion of the tasks, the preschooler will return to the virtual environment for a new task.

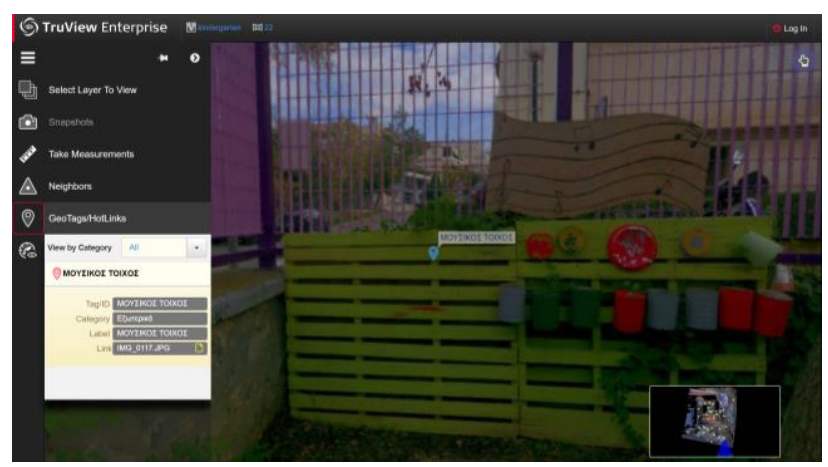

Fig. 7. Example of a geo-tagged object (music wall) with metadata information

\section{SYSTEM EXPERIMENTATION}

\subsection{Game tasks}

The digital application that is presented here has the significant advantage of representing a space with which children are already familiar. Therefore, it is much easier for them to understand spatial qualities and built new knowledge based on their pre-existing experiences. In addition, it is an open and flexible environment that teachers, after relevant training, can adjust to kindergarten's curriculum and children's needs as well. They can plan and add new learning activities depending on the topic they are working on and the interests of the children, to adjust what does not work or is not well understood by the children and so on. The possibilities are endless and with the storage option provided, a ready-made scenarios and activities file can be gradually created that can be used repeatedly.

The simple learning scenario that is presented below is for the first steps of using the $3 \mathrm{D}$ application. It has been designed to be developmentally appropriate and attractive with a variety of activities and is fully integrated into National Curriculum for Kindergarten. The aims and objectives of the scenario come from the subject areas of Mathematics and ICT and are as follows:
- $\quad$ children to identify and describe places, facilities and routes in the area as different reference systems using simple spatial concepts (straight, right, left, in front, behind, front, back)

- to recognize simple situations when they see them from a different angle/perspective

- $\quad$ to explore, experiment and discover knowledge using digital apps

- to explore and familiarized with a digital 3D environment

- to have fun

The user scenario implemented in the game and described herein is called "Learning the premises of our kindergarten". A few activities were set-up and are suggested to be used after the children have become acquainted with the kindergarten premises and their functions through a variety of organized psychomotor games and activities.

\section{Activity 1: Join us}

The child user should follows the correct path to go to his/her classroom (outside entrance-yard-building entrance-corridorclassroom entrance-guardrail). During the tour the child is encouraged to express himself/herself verbally and describe his/her movements. For the evaluation at the end of the activity the child is asked to describe how easy or difficult it seemed to navigate and in case of difficulty, to try and specify what made it difficult. The teachers also record their own observations about the time it took to complete the activity, the vocabulary the child has used and other important aspects of learning.

\section{Activity 2: Time for painting}

It is time for painting but what a misfortune! The coloured pencils have fallen from their box and are scattered everywhere in the classroom. The child user is asked to locate the scattered coloured pencils in the room and collect them. When successful, the child can open a painting application to paint.

\section{Activity 3: Play games}

The activity resembles free play in the activity corners of the classroom. The child chooses a corner and plays. In each corner there will be a hyperlink that will lead to a corresponding game. Examples of the games implemented in the developed application are: recognition of a musical instrument that is placed on the music wall, a digital puzzle on the table, narration of a fairy tale in the library, a memory game in the little house with house sounds.

\section{Activity 4: Hidden photos}

The purpose of the activity is to use photos from the school area that have been taken either from a strange angle or with a large zoom and the child must be able to locate where they come from and go to the specific tag to open the photo. The photos are opened sequentially based on their numbered geo-tag.

\subsection{Game experimentation}

In this work the developed serious game was tested by a small group of pre-school children that attend the specific school, so they were familiar with the virtual environment of the game. The children were asked to share their experience through a simple questionaire that was read to them by their parents regarding how the different components of the game created a positive emotional reaction. The group of children consisted by both boys and girls. 
The questionnaire examined the childrens' covert time on task and satisfaction with the design of the game. In total there were a number of simple statements in the questionnaire related to the child's satisfaction concerning three aspects: display interface (seeing the information), navigation interface (movement from place to place) and control interface (use of icons). The questionnaire was based on those developed by Shneiderman (1992) and Snir (1989) and were suitably adapted for this work. The grading for the above three aspects was kept simple in a three-level scale (bad, good, excellent).

The results indicated that a slight difference was found between boys and girls regarding time on task. Boys appear to pay more attention to the work with computers than girls. Regarding display interface, difference between boys and girls were found in the following subjects: Girls prefer talking during the game. Girls more than boys like seeing the colourful models than the one-coloured model on the computer screen. Regarding the navigation interface, it seems that boys more than girls like the screen changing at once. Regarding the mouse interface, findings indicate that boys do not like it when only part of the screen changes. Both boys and gils navigate confidently through the model. Based on the overall experience, it was seen a different attitude between boys and girls toward different issues summarised as boys showing interest during the game, while girls having more interest in the visual side of the game. These findings corroborate with similar findings in the literature (e.g. Severiens and Dam, 1997).

Clearly, children of preschool age learn about the world that surrounds them through experience and interaction with their environment. Children's understanding of space is through their awareness of themselves in relation to the people and objects around them. They develop this spatial sense exploring their world through their body, their senses and their movements and when they come to kindergarten, they already have various experiences about space. Teacher's role is to support children to expand their experiences and transform them to knowledge, providing meaningful and developmentally appropriate materials and opportunities for exploration. The use of a variety of concrete as well as digital, education materials along with teacher's guidance and support will help children understand and develop key aspects of spatial thinking.

In this context the use of a 3D digital environment, especially one that depicts something very familiar where children interact every day and in many ways (their kindergarten) can be a very useful educational material that will support further children's spatial learning and understanding. This tool is not intended to replace real world exploration and interaction. Instead it is aimed to extend the experience that children have got through this exploration and interaction.

\section{CONCLUDING REMARKS}

The use of serious games in education connects the needs of a new generation of learners that use digital devices to communicate, express and understand the world around them. There are intrinsic learning qualities that challenge and foster children and improve their skills by involving a process of trial and error.

One of the important quality features of serious games in early education is the capacity to include a rich variety of visual and intellectual stimuli that triggers children's motivation to focus on the task and increase their familiarity with thematic concepts. Therefore, it is essential to link game concepts to real life, explaining key actions in the digital game that mirror real life concepts.

Thus, there is a need for a well-established and appropriate implementation of instructional principles to provide a common ground for game designers and educators to collaborate and effectively incorporate games into the curricula. The game design must encompass all three learning domains: cognitive, affective and psychomotor, if content learning is to take place as a result of playing serious games.

The developed game presented in this work refers to the school environment of the preschoolers and has a simple strategy of accomplishing missions involving a sequence of small tasks, each of which has a specific, limited instructional target. The game is mostly in navigation mode (inside buildings or outdoors) and does not follow a detailed story specification. The complexity of the tasks can grow up gradually towards ever more complex objectives. The game allows teachers to develop/customize content depending on the learning goals.

For serious games to be considered a viable educational tool, they must provide some means of testing and progress tracking. The testing must be recognizable within the context of the education or training they are attempting to impart. In this work only a short assessment was performed but there is need for further testing and evaluation.

\section{ACKNOWLEDGEMENTS}

The authors acknowledge the help of the teachers for their valuable input in designing the digital tasks and the pre-school children in testing the developed platform.

Also, the authors would like to thank Ordnance Survey GB (www.ordnancesurvey.co.uk) and 1Spatial (www.1spatial.com/) for sponsoring the publication of this paper.

\section{REFERENCES}

Bellotti, F., Berta, R., De Gloria, A., 2010. Designing Effective Serious Games: Opportunities and Challenges for Research. Int.l Journal of Emerging Technologies in Learning (IJET), Special Issue: Creative Learning with Serious Games Vol. 5.

Clements, D., Sarama, J., 2002. The Role of Technology in Early Childhood Learning. Teaching Children Mathematics, vol. 8

Dalgarno, B., Lee, M., 2010. What are the learning affordances of 3-D Virtual environments?. British Journal of Educational Technology. 41:10-32. 10.1111/j.1467-8535.2009.01038.x.

De Gloria, A., Bellotti, F., Berta, R., 2014. Serious Games for education and training. Int. J. of Serious Games 1(1).

EAICT (Educational Academic Institute of Computer Technology) 2011. Educational Material for the Training of Teachers in the Training Support Centers-Issue 2b: PE60Publishing, EEATY Department of Education and Training, Patras, Greece. 
Fokides, E., 2020. Digital educational games in primary education: revisiting the results of the research projects of the ETiE initiative. In: Linda, Daniela (ed.), Epistemological approaches to digital learning in educational contexts, Routledge, London and New York.

Gardiner, H., 1983: Frames of mind: the theory of multiple intelligences. New York, Basic Books.

Gee, J.P., 2003: What video game have to teach us about language and literacy, NY: Palgrave Macmillan.

Gillespie, H. 2006: Unlocking Learning and Teaching with ICT: Identifying and Overcoming Barriers, Routledge.

Gilligan, K.A., Flouri, E., Farran, E.K., 2017. The contribution of spatial ability to mathematics achievement in middle childhood. J Exp Child Psychol. 163:107-125.

Haugland, S.W., 2000. Early childhood classrooms in the 21st century: Using computers to maximize learning. Young Children, 55: 12-18.

Kiili, K., 2007.Foundation for Problem-Based Gaming. British Journal of Educational Technology - Special issue on GameBased Learning, Vol. 38.

Kjällander, S., Moinian, F., 2014. Digital tablets and applications in preschool - Preschoolers' creative transformation of didactic design. Designs for Learning, Vol. 7. 10.2478/dfl-2014-0009.

Kirschner, P.A., Sweller, J., Clark, R.E., 2006. Why minimal guidance during instruction does not work: an analysis of the failure of constructivist, discovery, problem-based, experiential, and inquiry-based teaching. Educational Psychologist 41 (2).

Linda, D. (ed.) 2020. Epistemological approaches to digital learning in educational contexts, Routledge, London and New York.

Martínez, A.C.., Martínez-Segura, M-J., Laguna-Segovia, M., Pérez-López, D.C., Contero, M., 2014. Supporting Learning with 3D Interactive Applications in Early Years. In: Zaphiris Panayiotis, Ioannou Andri (eds) Learning and Collaboration Technologies. Technology-Rich Environments for Learning and Collaboration. LCT 2014. Lecture Notes in Computer Science, vol 8524. Springer, Cham, pp 11-22

Mohammad, M., Mohammad, H., 2012. Computer Integration into the Early Childhood Curriculum. Education, 1(20): $97-$ 116.

Newcombe, N.S, Frick, A., 2010. Early Education for Spatial Intelligence: Why, What and How. Mind, Brain and Education 4(3):102-111.

Nikolopoulou, C., 2009. Information and Communication Technologies in Preschool Education, Integration, Use and Utilization. Patakis Publications, Athens.

Prensky, M., 2002. The Motivation of Gameplay or, the REAL 21st century learning revolution. On the Horizon. 10:5-11. $10.1108 / 10748120210431349$.

Ponticorvo M., Schembri M., Miglino O. (2019) How to Improve Spatial and Numerical Cognition with a Game-
Based and Technology-Enhanced Learning Approach. In: Understanding the Brain Function and Emotions. IWINAC 2019. Lecture Notes in Computer Science, vol 11486. Springer, Cham.

Sarno, E., 2012. Exploring and enhancing Spatial Thinking: Links to Achievement in Science, Technology, Engineering and Mathematics? Review Int. Geographical Education Online 2(2).

Severiens, S., Dam, G.T., 1997. Gender and Gender Identity Differences in Learning Styles. Educational Psychology, 17(1, 2): 79-93.

Shneiderman, B., 1992. Designing The User Interface, Strategies for Effective Human- Computer Interaction. Mass: Addison Wesley.

Snir, N., 1989. The Media and The Student, The Influence of Educational Technologies (Computer, Television, Student's Notebook) on Achievement, Motivation and Time- On-Task. MA Thesis, Bar-Ilan University, Israel.

Surtees, A., Apperly, I., Samson, D., 2013. Similarities and differences in visual and spatial per-spective-taking processses. Cognition 129:426-438.

Verdine, B.N., Golinkoff, R.M., Hirsh-Pasek, K., Newcombe, N.S., 2017. I. Spatial skills, their development, and their links to mathematics. Monogr Soc Res Child Dev. 82(1):7-30.

Virvou, M., Katsionis, G., Manos, K., 2005. Combining Software Games with Education: Evaluation of its Educational Effectiveness. Educational Technology \& Society. Journal of International Forum of Educational Technology \& Society and IEEE Learning Technology Task Force, April 8(2).

Willis, J., 1996. A framework for task-based learning. Harlow, U.K., Longman Addison- Wesley.

Wong-Powell, J., 2020. Unpacking Digital Play In Children's Play. In Linda, Daniela (ed.), Epistemological approaches to digital learning in educational contexts, Routledge, London and New York.

Zaphiris, P., Ioannou, A. (eds) (2014) Learning and Collaboration Technologies. Technology-Rich Environments for Learning and Collaboration. LCT 2014. Lecture Notes in Computer Science, vol 8524. Springer, Cham

Zhang, X., Koponen, T., Räsänen, P., Aunola, K., Lerkkanen, M.K., Nurmi, J,E., 2014. Linguistic and spatial skills predict early arithmetic development via counting sequence knowledge. Child Dev. 85(3):1091-107. 